\title{
Literature Review on Farmland Landscape Pattern Change Analysis
}

\author{
Zhezhe $\mathrm{Mu}^{1,2,3, *}$ \\ ${ }^{1}$ Key Laboratory of Degraded and Unused Land Consolidation Engineering, Ministry of Natural Resources, xi'an 710021, China. \\ ${ }^{2}$ Shaanxi Provincial Land Engineering Construction Group Co., Ltd., xi’an 710075, China. \\ ${ }^{3}$ Institute of Land Engineering and Technology, Shaanxi Provincial Land Engineering Construction Group Co., Ltd., xi’an 710021, \\ China.
}

\begin{abstract}
Farmland landscape pattern refers to the composition and spatial distribution of landscape elements in a certain spatial range. Farmland landscape pattern formation has natural, historical, cultural and other factors. Since the reform and opening up, China 's rapid socio-economic development, urbanization and a series of social development caused a large number of land occupation, farmland landscape pattern has undergone major changes. Domestic and foreign scholars based on natural geography, landscape ecology, combined with $3 \mathrm{~S}$ technology, FRAGSTATES landscape index calculation method, from the aspects of landscape evolution process, landscape heterogeneity and diversity and landscape dynamics and driving factors correlation, analyzes the characteristics of regional landscape pattern change, and on this basis, analyzes the influence mechanism and correlation of landscape pattern succession. However, at present, most studies are based on the time axis, focusing on the changes of landscape patterns such as forests, wetland waters and towns. There are relatively few studies on the changes of farmland landscape patterns, and there are relatively few studies on the combination of time and space. Therefore, through the study and analysis of the characteristics of farmland landscape pattern change, the driving factors of landscape pattern change are known, and on this basis, the methods and ways of landscape pattern optimization are studied to provide scientific basis for constructing and optimizing farmland ecosystem, regional ecological network and protecting biodiversity.
\end{abstract}

Key words: Landscape; Landscape Pattern; Transfer Matrix; Landscape Index.

\section{Introduction}

Landscape is rich in connotation, including not only explicit content such as farmland, villages and ditches, but also implicit content such as farming culture, which is both a natural landscape and an artificial landscape. The formation of farmland landscape pattern is complicated due to historical, natural and cultural reasons. The scale, shape, structure and texture of farmland landscape are different, which is the result of the interaction of various complex natural and social conditions. Since the reform and opening up, with the rapid development of China ' $s$ economy, the process of urbanization is accelerating, the population is constantly concentrated in urban areas, the contradiction between urban development and agricultural land is prominent, the development of ' spread cake ' caused a lot of waste of land resources, high-quality farmland is occupied, so that the number of land for agricultural production is reduced and the quality of land is decreased, especially because the coordination and protection of resources and ecology are not fully considered in economic development, which makes the regional environment and ecological situation deteriorating. In addition, the implementation of household contract responsibility system has led to largescale changes in farmland landscape pattern, the gradual disappearance of concentrated large-scale farmland landscape, the reduction of landscape diversity and the destruction of ecosystem. In the study of farmland landscape pattern in China, most scholars draw lessons from foreign farmland landscape theory and research results, too much emphasis on the impact and role of biological and natural processes on farmland landscape pattern, and weaken the impact of human social activities on farmland landscape pattern, attach importance to the application of foreign research theory and results, and ignore the social and cultural background of these theories. Studying the evolution of farmland landscape pattern can find the evolution law of farmland landscape pattern under the background of rapid social and economic development, and in-depth study of the mechanism of the evolution of farmland landscape pattern under this background, provide opinions and suggestions for the construction and optimization of farmland landscape

\footnotetext{
* Corresponding author: muzhezhe@126.com
} 
pattern, the construction and optimization of ecological network, the protection of ecological system and the management of agricultural production.

\section{Research status}

The introduction and development of landscape ecology in China are relatively late. Since the 1980s, landscape ecology has been introduced into China. Many scholars have actively studied and explored the content and theory of landscape ecology with landscape pattern as the main research content. From the perspective of time, Xiao Duning and Zhao Yi analyzed the changes of landscape pattern in the western suburbs of Shenyang in recent 30 years with landscape diversity index as the research index, which opened the precedent of research and application of landscape pattern in China. Tian Qifan, Yan Haiping selected landscape indicators ( patch density, patch area, etc. ) that can represent the characteristics of the study area to study the landscape pattern change of Xishan National Forest Park in Beijing and explore its influencing factors ; taking Liaohe wetland as the research object, Wang Xianli and Xiao Duning analyzed the changes of landscape pattern, and found that the main landscape pattern of Liaohe wetland was dense corridor system, which was greatly affected by human activities. Chen Xuebo analyzed and studied the advantages and disadvantages of landscape index from two aspects of landscape type level and overall landscape level. Guo Hongbin and Huang Yixiong, supported by $3 \mathrm{~S}$ technology, used entropy method to analyze and evaluate different landscape patterns in Xiamen, and optimized its landscape structure and function. Ma Xiaofei selected remote sensing images of Ebinur Lake wetland in four periods to study and analyze the landscape pattern change of Ebinur Lake wetland and explore the relationship between landscape pattern change and ecological service value. Lin Junmin takes the landscape pattern change of Xiamen City as the research object, analyzes the change rule and provides suggestions for the landscape ecological construction of Xiamen City ; Supported by ArcGIS technology, Zhao Tingting studied and analyzed the change of farmland landscape pattern in Shunyi District of Beijing, and analyzed the influencing factors. Fu Meichen used historical literature analysis method to summarize the evolution law of general farmland landscape pattern.

In general, the research on landscape pattern in China is mainly from the perspective of natural geography and landscape ecology, and mainly focuses on the changes of landscape pattern such as forests, wetlands and cities. There are few studies on the changes of farmland landscape pattern. In terms of research scale, most of them are from the perspective of time, and summarize the evolution law of landscape pattern through the analysis of remote sensing images of a certain research area in the past $20-30$ years.

\section{Research method}

Most of the researches on landscape pattern are based on the theory, knowledge and model of landscape ecology to construct landscape model and calculate landscape index to reflect the spatial and temporal characteristics of landscape pattern.

(1) Literature analysis. By reading and accumulating a large number of literature on landscape pattern changes, we learn the theoretical knowledge of landscape ecology, understand the meaning of landscape index, analyze the research progress on landscape pattern at home and abroad, and be familiar with the hot issues of current research to ensure the scientificity of this study.

(2) RS technology. RS ( remote sensing ) technology is a technology that detects and identifies targets from electromagnetic wave, visible light and infrared ray that is reflected or radiated by the target from a long distance. Modern remote sensing technology mainly includes information acquisition, transmission, storage and processing, and its core component is the remote sensor to obtain information.

(3) GIS technology. GIS ( geographic information system ) technology is a specific and very important spatial information system. It is a technical system for collecting, storing, managing, computing, analyzing, displaying and describing relevant geographic distribution data in the whole or part of the Earth 's surface (including the atmosphere ) space with the support of computer hardware and software systems. For the processing of spatial data, most researchers use GIS as the support, which makes the complex traditional spatial tasks simple and easy, and can effectively analyze and explain the relationship between geographical features and spatial patterns.

(4) Selection and Calculation of Landscape Index. Landscape pattern index can quantitatively reflect the characteristics of landscape pattern. In the analysis of landscape spatial pattern, the selection and calculation of landscape index is a common method. Landscape index is usually calculated from three levels : plaque level, plaque type level and landscape level. Many scholars choose the landscape index which can represent the characteristics of the study area, calculate the landscape index on different scales, analyze the change, summarize the law, and combine the meaning expressed by the landscape index to obtain the characteristics of landscape pattern change. Because the analysis of patch level and type level often belong to a landscape type, the landscape pattern index of the two has corresponding repeatability. Therefore, in practical applications, scholars often merge patch level and type level into one class, which is simplified as landscape type level characteristics and landscape overall level.

(5) Transfer probability matrix. The transition probability matrix was proposed by Markov, a Russian mathematician, who discovered in the early 20th century that in the transition of some factors in a system, the nth result is only affected by the n-1 result, that is, only related to the current state, but not to the past state. Each element of the matrix is nonnegative, and the sum of the elements of each row is equal to 1 . Each element is expressed by 
probability and is transferred to each other under certain conditions, so it is called transfer probability matrix.

In the analysis of landscape pattern index, many researchers used this method to study the transformation characteristics, relationships and transformation ratios between various landscape types through the transfer matrix method.

\section{Research progress}

\subsection{Research on related concepts}

(1) Landscape. The term landscape is widely used, but there are also different understandings. Speaking of landscape, we usually understand it as natural existence, artificial construction, as well as urban, forest and farmland landscape, but most of them reflect the topography, geomorphology, scenery or comprehensive terrain characteristics of a geographical area. Landscape understanding can be from a narrow and broad perspective. Landscape in a narrow sense is what we usually call a landscape in a general sense, which is limited to a mesoscale range ( tens of kilometers to hundreds of kilometers ). Based on human sensory cognition, it reflects human subjective will, such as woodland, grassland, farmland and residence. The landscape in a broad sense is centered on organisms and has a wide range, which can be small to a single pond or large to a global scale. The most prominent feature is that it reflects the multi-scale and hierarchical structure of the ecological system. The landscape in this study is defined in a broad sense as a mosaic composed of heterogeneous landscape components ( patches, corridors, and matrices ). (2) Landscape pattern. Landscape pattern generally refers to the composition and spatial distribution of landscape. With the deepening of landscape ecology research, Fu Bojie defined landscape pattern as the spatial distribution and combination characteristics of landscape components, that is, the size, shape and distribution of patches, which only contain spatial characteristics. Bi Junliang defines the landscape pattern as : the structural characteristics of landscape space, as the comprehensive embodiment of landscape diversity and heterogeneity in the study space, the mosaic of different landscape types. Yang Zhuo takes the landscape elements as the breakthrough point, and defines the landscape pattern as : the distribution of landscape elements dispersed or aggregated in space, which is the performance of the spatial distribution and combination characteristics of landscape components. Zhao Zhongjian believes that landscape pattern is the result of interaction between biological natural process and human disturbance, which is reflected by landscape elements such as patch shape, corridor composition and road network distribution. In this study, the landscape pattern is defined as : within a certain spatial range, the composition of the landscape elements and spatial distribution characteristics.

(3) Plaques. Patches, also known as patch or patch, are scale-dependent, different from the surrounding environment in nature or appearance, showing obvious boundaries, and have certain internal homogeneity of spatial entities. In a broad sense, patches can be alive, such as flora and fauna, forests, grasslands, etc. Can also be lifeless, such as residential areas, geological landforms. In the narrow sense, patches only indicate plant communities. The study of patches in landscape ecology is of great significance. The size of patches not only affects the survival of species, but also affects the necessary energy and nutrients for species survival. Generally, the larger the patch area is, the higher the species diversity is. The change of the number of patches reflects the existence and absence of animal and plant habitats. The decrease of the number of patches means the decrease of biological habitats. In this study, the concept of plaque reference Zhang $\mathrm{Na}$ and other scholars point of view, defined as : refers to the surrounding environment in appearance or nature is different, but also has a certain internal homogeneity of the space part.

(4) Corridor. Corridors refer to narrow areas that are distinct from both sides of the matrix, such as forest belts, rivers, riparian vegetation, highways, etc. Corridor can be regarded as a special form of plaque, and it is also a bridge and link connecting the plate. It is generally believed that the patches with length-width ratio at least 10-20, and the landscape components that are segmented and connected by patches can be considered as corridors. Corridor affects the connectivity between patches to a large extent, and also affects the exchange of nutrients and energy between patches, which plays an important role in the protection of biodiversity. In this study, corridors are defined as linear or zonal landscape elements with channel or barrier functions, which are important bridges and links to connect patches. It is different from both sides of the matrix, can be seen as a linear or banded plaque.

(5) Matrix. Substrate is also known as the background, basement, etc., is the widest range, the largest distribution area, the best connectivity, dominant landscape components. Matrix may be a single landscape component, or heterogeneous mixture, to a large extent determines the nature of the landscape, by affecting energy, species and species flow, leading landscape dynamics and functions. The concept of matrix in this study is : the background of landscape is the landscape elements with the best area connectivity and the strongest landscape control.

\subsection{Research content}

The research on landscape pattern mainly analyzes and describes the process of landscape evolution, landscape heterogeneity and diversity, and the correlation between landscape dynamics and driving factors. Pattern problem, heterogeneity problem and scale effect problem are several key areas of landscape structure research.

Pattern research includes landscape diversity analysis, fragmentation analysis, adjacency analysis and heterogeneity analysis. Although many people are trying to construct a new landscape pattern index, they all belong to the correction and improvement of the existing index, and there is no new description idea. For landscape pattern research from the perspective of time and space more. Through remote sensing images of different periods, with ENVI, ArcGIS and other software as technical support, 
the evolution law and influence mechanism of landscape pattern were studied and analyzed. From the perspective of space, the focus is on the statistical analysis of landscape spatial distribution changes and the calculation and analysis of landscape pattern index to understand the distribution characteristics of landscape pattern in space. Bi Junliang, Zhao Tingting, Zhang Guokun combined time and space to analyze the landscape pattern changes in the study area, and in-depth study of the driving forces leading to this change. However, the research on the driving factors of landscape pattern change is mainly qualitative or simple quantitative analysis of landscape pattern change in a single study area. There are few studies on different spatial scales and time scales. It is one of the main aspects to study the formation and evolution of agricultural landscape pattern from the perspectives of human geography, landscape ecology and aesthetics. In addition, some studies have begun to focus on the relationship between agricultural landscape and landscape architecture, or analyze the composition of agricultural landscape. Through the calculation of landscape index in landscape ecology, combined with the meaning expressed by landscape index, it reflects the change of landscape pattern in the study area, and discusses the mechanism of causing this change. At the same time, through the establishment of landscape model and ecological network model, it aims to provide reference for the optimization of landscape pattern and the construction of farmland ecosystem network.

\section{Summarize}

Studying the change of farmland landscape pattern plays an important role in constructing and optimizing farmland ecosystem. Chinese scholars mainly study the formation and evolution of landscape pattern from the perspectives of human geography, landscape ecology and aesthetics. It can be seen that the changes of landscape pattern, landscape heterogeneity and scale effect are the key issues in the study of landscape structure. The research contents of landscape pattern include landscape diversity analysis, fragmentation analysis, adjacency analysis and heterogeneity analysis. Most researchers from the perspective of time, through the selection and calculation of landscape index, analyze the transfer changes between the landscape elements, and analyze the mechanism of these changes. On this basis, combined with the background of social development, the purpose is to understand the change law of landscape pattern through research, in order to provide scientific reference for the construction and optimization of farmland landscape pattern, agricultural ecosystem and ecological network.

\section{Acknowledgments}

Project Fund : 2021WHZ0093 - Urban Landscape Ecological Effect Research and Demonstration Application.

DJNY2021-34- Internal Research Project of Shaanxi Land Engineering Construction Group.
Author Information: Mu Zhezhe ( 1994- ), male, Qingyang, Gansu, master, assistant engineer, mainly engaged in land resources management, land economics, land engineering research.

\section{References}

1. Z L He. Investigation of agricultural landscape in northeast area. Beijing Jiaotong University. 2013,6 : 9-10.

2. $\mathrm{M} \mathrm{C} \mathrm{Fu}, \mathrm{Z} \mathrm{Q} \mathrm{Hu}, \mathrm{G} \mathrm{G}$ Wu. Analysis of farmland landscape pattern evolution. Journal of Agricultural Engineering. 2005,6 ( 6 ) : 2-4.

3. Z J Zhao. Study on land transfer way of farmland landscape spatial pattern evolution. Anhui Agricultural Science. 2013, 41 ( 4 ) : 1795-1798.

4. D N Xiao, Y Zhao, Z W Sun, etc. Study on landscape pattern change in west suburb of Shenyang. Applied Ecology. 1990, 1 ( 1 ) : 75-84.

5. Q F Tian, H P Yan, Y Liu, etc. Preliminary study on landscape pattern of Xishan National Forest Park in Beijing. Journal of Beijing Forestry University. 1994, $03: 8-16$.

6. X L Xiao, D N Xiao, R C Bu, etc. Landscape pattern analysis of Liaohe delta wetland. Journal of Ecology. 1997, 03 : 317-323.

7. W B Chen, D N Xiao. Landscape index classification, application and construction. Applied Ecology. 2002, 13 ( 1 ) : $121-125$.

8. H B Guo, Y X Huang, G F Ye, etc. Evaluation and optimization of urban ecological function network in Xiamen. Journal of Natural Resources. 2010, 01 : 7179.

9. X F Ma. Study on the relationship between landscape pattern change and ecological service value of Ebinur Lake wetland. Xinjiang Normal University. 2017, 5 : 19-21.

10. Z M Lin. Study on landscape dynamic change and ecological environment effect in Xiamen. Fujian Normal University. 2007, 4 : 87-89.

11. T T Zhao, F R Zhang, Z G Niu, etc. Study on farmland landscape pattern change in Shunyi District of Beijing. Regional research and development. 2009,6 ( 3 ) : 2-6.

12. K L Chen. Study on the evolution and optimization strategy of urban ecological landscape pattern in karst area - - Anshun as an example. Huazhong University of Science and Technology. 2016.5 : 1213.

13. B j Fu, L D Chen, K M Ma, etc. Landscape ecology principles and applications (Science Press, Beijing, 2001).

14. J G Wu. Landscape ecology-pattern, process, scale and grade ( second edition) (Higher Education Press, Beijing, 2007) . 
15. N Zhang. Landscape ecology ( Science Press, Beijing, 2014) .

16. J L Bi. Analysis of forest landscape pattern changes and driving factors in the Yangtze River Basin from 1992 to 2012. Huazhong Agricultural University. June 2014 : 13-14.

17. Z Yang. Land use and landscape pattern change in typical agro-pastoral ecotone in Northeast China. Beijing Forestry University. 20144 : 8 - 9.

18. Y Zhao, Y H Li. Practical landscape ecology (Science Press, Beijing, 2001) .

19. G K Zhang, J H Lu, K S Song, etc. Landscape pattern changes in Zhenlai County of Jilin Province in recent 10 years. Journal of Ecology 2012,32 ( 12 ) : 39583965. 